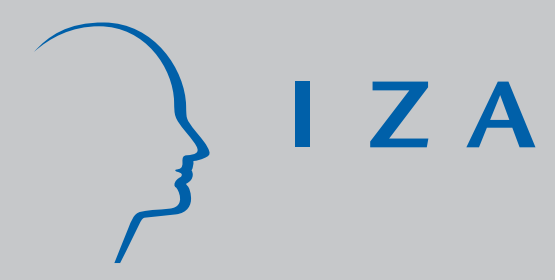

IZADP No. 2888

Intertemporal Labor Supply and Involuntary Unemployment

Peter Haan

Arne Uhlendorff

J une 2007 


\title{
Intertemporal Labor Supply and Involuntary Unemployment
}

\author{
Peter Haan \\ DIW Berlin and FU Berlin
}

\section{Arne Uhlendorff}

DIW Berlin and IZA

\section{Discussion Paper No. 2888 \\ June 2007}

IZA

\author{
P.O. Box 7240 \\ 53072 Bonn \\ Germany
}

Phone: +49-228-3894-0

Fax: +49-228-3894-180

E-mail: iza@iza.org

\begin{abstract}
Any opinions expressed here are those of the author(s) and not those of the institute. Research disseminated by IZA may include views on policy, but the institute itself takes no institutional policy positions.

The Institute for the Study of Labor (IZA) in Bonn is a local and virtual international research center and a place of communication between science, politics and business. IZA is an independent nonprofit company supported by Deutsche Post World Net. The center is associated with the University of Bonn and offers a stimulating research environment through its research networks, research support, and visitors and doctoral programs. IZA engages in (i) original and internationally competitive research in all fields of labor economics, (ii) development of policy concepts, and (iii) dissemination of research results and concepts to the interested public.
\end{abstract}

IZA Discussion Papers often represent preliminary work and are circulated to encourage discussion. Citation of such a paper should account for its provisional character. A revised version may be available directly from the author. 


\section{ABSTRACT}

\section{Intertemporal Labor Supply and Involuntary Unemployment}

In this paper we develop a model to consistently estimate the intertemporal labor supply behavior on the extensive margin (participation decision) and the intensive margin (working hours decision). In this framework we distinguish between voluntary non-participation and involuntary unemployment which is caused by labor market rationing and model the dynamics of labor supply by accounting for true state dependence and unobserved effects. Our approach follows the empirical literature on life cycle employment based on approximate decision rules. However, in contrast to previous studies, this framework allows us to test for true state dependence of voluntary non-participation, involuntary unemployment, full-time work and over-time work. Moreover, we derive consistent estimates of intertemporal labor supply elasticities over time and asses the bias of short- and long-run elasticities derived in a pure choice model of labor supply.

JEL Classification: $\quad$ C23, C25, J22, J64

Keywords: intertemporal labor supply behavior, transitions on the labor market, state dependence, involuntary unemployment

Corresponding author:

Arne Uhlendorff

DIW Berlin

Mohrenstraße 58

10108 Berlin

Germany

E-mail: auhlendorff@diw.de

\footnotetext{
* We would like to thank Richard Blundell, Dirk Hofmann, Victoria Prowse, Viktor Steiner and Katharina Wrohlich for helpful comments. Financial support by the German Science Foundation (DFG) in the priority program "Potentials for more flexibility on heterogenous labor markets" is gratefully acknowledged. The usual disclaimer applies.
} 


\section{Introduction}

In this paper we develop a model to consistently estimate the intertemporal labor supply behavior on the extensive margin (participation decision) and the intensive margin (working hours decision). In this framework we distinguish between voluntary non-participation and involuntary unemployment which is caused by labor market rationing and we account for the effect of true state dependence. True state dependence measures the causal effect of the previous labor market states on the current outcome. The proposed model fills a gap in the existing literature on labor supply, since previous studies do either not reflect the dynamics in labor supply behavior or are based on the assumption of a pure choice model which implies that unemployment is voluntarily chosen.

Several studies have previously accounted for involuntary unemployment in labor supply estimations. The starting point is Blundell, Ham, and Meghir (1987) who extend the standard model of female labor supply by introducing a probability of rationing that results in a double-hurdle model. Hogan (2004) applies this approach to a panel structure, relaxing the IIA hypothesis through nested logit modeling. Bingley and Walker (1997), Duncan and MacCrae (1999) and Bargain, Caliendo, Haan, and Orsini (2006) combine a latent model for the probability of involuntary unemployment with a discrete-choice model of labor supply which captures both the extensive and the intensive margin. Laroque and Salanie (2002) model the labor supply of French women by introducing classical unemployment due to the censorship of the minimum wage; other involuntary unemployment is a residual category gathering all other explanations (frictional or business cycle unemployment). The findings of these studies emphasize the importance to control for involuntary unemployment when analyzing the labor supply behavior.

All above-mentioned studies model labor supply in a static framework. Yet, the assumption of a static labor supply behavior has been rejected by numerous studies that find strong evidence for true state dependence in the labor supply behavior, e.g Heckman (1981a). There exists a large body of literature modeling and estimating the labor supply behavior in an intertemporal context, including multi period two-stage budgeting models (e.g. Blundell and Walker, 1986), dynamic labor supply models 
based on approximate decision rules (e.g. Hyslop, 1999) or structural forward looking optimization models of life cycle employment (e.g Francesconi, 2002 ).

Of particular interest for this paper are those few studies that focus on the dynamics of the labor supply behavior on both the extensive and the intensive margin. Prowse (2005) analyzes transitions of women between no work, part-time and full-time work in an intertemporal context. Using a discrete choice model, she shows that true state dependence is present in both full-time and part-time employment. Michaud and Vermeulen (2004) model the labor supply and retirement decision of households in the US in an intertemporal framework that accounts for the intensive and extensive margin. Haan (2006) estimates the labor supply of married and cohabiting women in Germany in an intertemporal discrete choice model and derives labor supply elasticities in the short and in the long run. He finds that state dependence is significantly present and explains the difference in short- and long-run labor supply effects. The study of Francesconi (2002) slightly differs from the above-mentioned as he proposes a fully structural model of fertility and labor supply which includes part-time and full-time work. One key finding of his study is the strong persistence of labor supply behavior. The shortcoming of all these studies on the intertemporal labor supply behavior, however, is that the working behavior is modelled in a pure choice model not reflecting potential labor market restrictions 1

The framework suggested in this paper combines the ideas of the discussed literature. More precisely, we combine a structural intertemporal discrete choice model of labor supply with a reduced form risk model of labor market rationing. Our approach is similar to life cycle models of employment based on approximate decision rules such as Keane and Wolpin (2001), Hyslop (1999) or Del Boca and Sauer (2006). The econometric specification accounts for the non-randomness of the initial labor market state, captures unobserved effects non-parametrically and allows for free correlation between the different employment processes. The analysis is based on a detailed microsimulation model for Germany (STSM) which maps the relevant regulations of the German tax and benefit system. A detailed modeling of the net household income is in particular

\footnotetext{
${ }^{1}$ In addition to the above mentioned literature, there exist several studies analyzing the transition from unemployment to employment and non-participation in a duration framework, e.g. Frijters and van der Klaauw (2006). The main difference is, beyond the time framework, the inclusion of only one initial state (unemployment).
} 
important for the estimation of the labor supply behavior as this is the most accurate way to describe work incentives in the household context (Laroque and Salanie, 2002). Moreover, the detailed modeling of the work incentives is necessary to capture persistence in the working behavior which is not due to true state dependence. In thus far, we go beyond most of the existing literature on state dependence which only considers gross wage or human capital effects but not the effects of the tax and transfer system.

The proposed model extends the previous literature in two dimensions. The first extension is the differentiation between the causal effect of voluntary and involuntary unemployment in the previous period on the current labor market status. Second, it provides a framework to consistently estimate the labor supply behavior over time. Our analysis is complementary to the findings of Hajivassiliou and Ioannides (2007) who analyze the jointness of labor market and liquidity constraints in a dynamic framework. The focus in our paper is solely on the constraints of the labor market, yet allows to analyze the labor supply behavior.

We apply the intertemporal labor supply models with demand side rationing to consistently estimate the labor supply behavior of men over time. We use panel data from the German Socio Economic Panel (SOEP) that yield detailed information about the employment behavior, the employment history and about socio-demographic and economic variables over time. To identify the rationing on the labor market we merge detailed regional labor market indicators to the micro data.

We find that true state dependence is significantly present between the different labor market states. Moreover, our results stress the necessity to account for involuntary unemployment when analyzing the intertemporal labor supply behavior, since state dependence differs significantly conditioned on involuntary unemployment and voluntary non-participation. We find that intertemporal labor supply elasticities differ when accounting for involuntary unemployment. Elasticities derived in an unconstrained pure choice model are significantly upward-biased. This holds true for short-run and long-run labor supply elasticities which are derived using Markov-chains. 


\section{Data and Descriptive Statistics}

This study is based on the SOEP which is a representative sample of over 12,000 households living in Germany with detailed information about the working behavior and socio-economic variables on a yearly basis $2^{2}$ For this analysis, we draw on unbalanced panel data with consecutive observations for the years 2000 - 2005 which yield retrospective information for the fiscal years 1999 - 2004. The regional labor market indicators, which are necessary for the identification of involuntary unemployment, are collected by the Employment Office separately for 438 geographical regions $3^{3}$ This information can be exactly matched to the micro information of the households.

Labor supply behavior differs between men and women and has to be analyzed separately. Labor market participation is significantly higher for men and while parttime work is relatively common for women, men tend to work full-time or over-time. In this study, we concentrate on the labor supply behavior of men. Partly, we focus on this group for technical reasons. When studying the working behavior of men it is not necessary to account for peculiarities of part-time work and even more important for the potential endogeneity of fertility. Moreover, for men the impact of involuntary unemployment on the labor supply behavior is particularly strong. Bargain, Caliendo, Haan, and Orsini (2006) find that for groups with a relative large share of voluntary non-working, such as married women, labor supply elasticities do hardly change when accounting for involuntary unemployment. For men, in contrast, for which the share of involuntary unemployed is relatively large, they find a severe upward bias when not accounting for demand side rationing. We further restrict our sample to men older than 25 and younger than 59 years. This is motivated by the educational and the retirement schemes in Germany. Lastly, we exclude self-employed, retired and men in full-time education as their labor supply behavior substantially differs from the rest of the population. This results in a sample with 26667 observations.

\section{Working Behavior of Men}

Figure 1 shows the distribution of weekly working hours in our sample of men. We find that roughly $10 \%$ of the men do not work. This group includes both voluntary

\footnotetext{
${ }^{2}$ For a detailed description of the data set, see Haisken De-New and Frick (2005).

${ }^{3}$ Source: Arbeitslose nach Kreisen, Bundesagentur für Arbeit.
} 
Figure 1: Working behavior of men

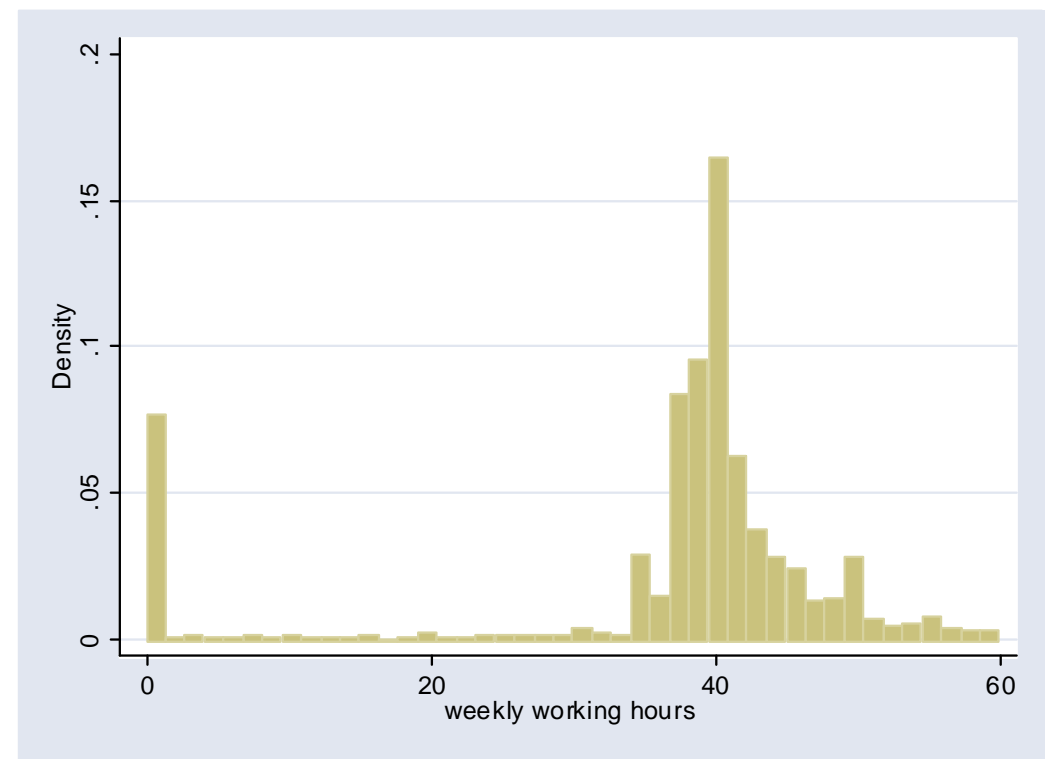

Notes: Weekly working hours are reported contractual hours plus reported paid over-time. Men are aged between 25 and 59. The distribution is censored at 60 hours per week which excludes about $2 \%$ of the relevant population.

Source: SOEP, $2000-2005$.

non-participants and involuntary unemployed. As stressed above, hardly any men work part-time. Only $3 \%$ of the working men work less than 35 hours per week. Thus, the vast majority of men works either full-time, defined as up to 40 hours per week, or more than 40 hours which is classified as over-time.

This peaked distribution of male working hours motivates why we model the labor supply behavior of men on the extensive and intensive margin in a discrete framework rather than assuming a continuous specification of working hours. In addition, the discrete choice approach provides the advantage to model complex nonlinearities in the budget function of a household in a straight-forward way. Thus, to describe the male working behavior we distinguish between non-participation, full-time work and over-time work 4

Table1 shows the relative share of men observed at the discrete alternatives and the average working hours for each alternative. For full-time work the average amounts to

\footnotetext{
${ }^{4}$ In previous research we have shown that labor supply elasticities are robust to the choice of the discrete working alternatives with and without part-time choices for men (Bargain, Caliendo, Haan, and Orsini, 2006).
} 
Table 1: Discrete Working Hours of Men

\begin{tabular}{lcccc}
\hline \hline & & & & \\
& & & & \\
& & & & \\
& & & \\
Non-Participation & 0.10 & 0 & 14.83 & 44.24 \\
Full-Time & 0.52 & 36.94 & 21.95 & 42.22 \\
Over-Time & 0.38 & 47.33 & 23.30 & 41.72 \\
Average & 36.48 & 21.60 & 42.27 \\
\hline \hline
\end{tabular}

about 37 hours per week, for over-time to about 47 hours. These average hours define the discrete working alternatives. Men at the different working alternatives differ by wages and in the age structure $5^{5}$ As expected, gross hourly market wages which are a measure of productivity are increasing with the observed working hours, while the average age is with over 44 years higher for the non-working than for the working men.

\section{Voluntary and Involuntary Unemployment}

As stressed above, the group of non-working men consists of voluntary non-participants and of the involuntary unemployed. Thus, in the paper we follow the view of Ashenfelter (1980) that unemployment can be a constraint on choice rather than the result of it. In line with e.g. Bingley and Walker (1997) we define individuals as voluntary unemployed or not participating if they do not search for a job. These individuals do not want to work for their market wage. In contrast, searching individuals which are classified as involuntary unemployed, are willing to work at their expected market wage (for a similar classification see Blundell, Ham, and Meghir, 1987). These individuals are involuntary unemployed because of institutional regulations, such as minimum wages or collective bargaining agreements or because of cyclical unemployment (Laroque and Salanie, 2002). The SOEP yields information to identify the involuntary unemployed. Each potential worker is asked (i) whether he has actively searched for a job within the

\footnotetext{
${ }^{5}$ For persons not employed in the month preceding the interview, gross hourly wages are estimated by applying a two-stage estimation procedure with a Heckman sample selection correction. Estimation results can be obtained on request.
} 
Table 2: Discrete Working Hours of Men with Rationing

\begin{tabular}{lcccc}
\hline \hline & & & & \\
& Share & Hours & Wages & Age \\
Vol. Non-Participation & 0.05 & - & 14.98 & 45.97 \\
Inv. Unemplyment & 0.05 & - & 14.70 & 42.77 \\
Full-Time & 0.52 & 36.94 & 21.95 & 42.22 \\
Over-Time & 0.38 & 47.33 & 23.30 & 41.72 \\
& & & & \\
Average & & 36.48 & 21.60 & 42.27 \\
\hline \hline
\end{tabular}

Notes, see Table 1

last four weeks and (ii) whether he is ready to take up a job within the next two weeks. We follow the ILO definition and treat those unemployed who answer both questions positively as involuntary unemployed or rationed.

Table 2 shows that around half of the non-working men, or $5 \%$ of the overall population are involuntarily unemployed according to this definition ${ }^{6}$ While the expected gross hourly wages do hardly differ between the involuntary unemployed and the voluntary non-participants we find an interesting difference in the age structure. Voluntary non-participants are on average about three years older than involuntary unemployed or working men. This reflects that the search intensity of non-working men decreases when approaching retirement age. 7

Involuntary unemployed are rationed by the demand side of the labor market, since they do not find work given their productivity although their labor supply is positive. In the empirical analysis we identify the individual probability of rationing using aggregate variables describing the situation on the regional labor market and individual characteristics. The regional labor market indicators are collected on county level, 438 for Germany, and provide a large source of variation which is necessary for identification in the estimation 8

\footnotetext{
${ }^{6}$ Note that these rates differ from official unemployment statistics since their denominators contain some of the inactive population (precisely the voluntary unemployed) and also because of selection criteria.

${ }^{7}$ The Appendix yields more descriptive statistics of the control variables used in the estimation.

${ }^{8}$ The key variable, the regional unemployment rates varies between about $2 \%$ to more than $30 \%$ with an average rate of 11.68 and a variance of 33.34 .
} 
Table 3: State Dependence: Descriptive Evidence

\begin{tabular}{l|cccc}
\hline \hline & Vol. Non-Part. & Inv. Unempl. & Full-Time & Over-Time \\
\hline Vol. Non-Part. t-1 & 59.56 & 17.07 & 15.86 & 7.51 \\
Inv. Unempl. t-1 & 16.39 & 48.02 & 24.01 & 11.57 \\
Full-Time t-1 & 2.03 & 3.03 & 76.27 & 18.68 \\
Over-Time t-1 & 1.41 & 2.18 & 26.54 & 69.86 \\
\hline \hline
\end{tabular}

The following working hours classifications (weekly) are used: 0, 0-40, >40. All numbers are in \%.

Source: SOEP, wave 2001-2005.

\section{State Dependence in Labor Supply: Descriptive Evidence}

We analyze the male labor supply behavior in an intertemporal framework. This allows us to study the persistence in the working behavior. More specific, we can analyze the effect of the previous working history on the current labor market state which is the state dependence in labor supply.

The following descriptive transition matrix of the male working behavior suggests a strong positive correlation between the working status in two consecutive periods. On the diagonal of the matrix we find very strong persistence in the working behavior over time. We find that more than $50 \%$ of the voluntary non-participants in period $t-1$ remain in this status in period $t$. For the involuntary unemployed this persistence is with close to $50 \%$ slightly lower. Conditional on working in the previous period the persistence of work is very high. More than $75 \%$ of the full-time working men and about $70 \%$ of those working over-time do not change their working status.

This descriptive evidence of working persistence does not describe the causal effect of the previous employment state on the current working behavior, which is true state dependence. In addition to state dependence, observable and unobservable characteristics explain the persistence. Thus, in order to disentangle the effect of true state dependence we need to control for these other sources of persistence.

\section{Theoretical Background}

In the following section, we present the theoretical framework for the empirical analysis of the intertemporal labor supply behavior of men. The intertemporal framework we present can be interpreted as a reduced-form dynamic life-cycle model. Thus, our approach is similar to Hyslop (1999), Keane and Wolpin (2001) or Del Boca and Sauer 
(2006) who formulate and estimate approximate decision rules rather than to fully dynamic life cycle models as e.g. Francesconi (2002) ${ }^{9}$

\subsection{Intertemporal Labor Supply without Involuntary Unem- ployment}

In our framework men maximize discounted remaining lifetime utility by choosing in each year $t$ among $j$ different labor market states ${ }^{10}$ As motivated in the previous section, we define three discrete choice alternatives, non-working $(j=0)$, full-time work $(j=1)$ and over-time work $(j=2)$. In the pure choice model we assume that each household can freely choose from this set of alternatives and does not face any demand side constraints. In order to keep the complexity of the model feasible we follow e.g. Laroque and Salanie (2002), and assume that the labor supply of the partner, here the women, is exogenously determined, thus men living in couples can be modeled as single decision makers in the same way as single men 11

We assume the following representation of the utility flow for each choice alternative at time $t$ :

$$
U_{i j t}=U\left(l_{i j t}, y_{i j t}, z_{i t-1}, x_{i t}, c_{i j}, \epsilon_{i j t}\right)
$$

The utility $U$ of a household $i$ contains an observable and an unobservable component. The observable component includes the leisure time of the men $l m_{i j t}$, and the net household income $y_{i j t}$ which includes female labor income in couple households and other sources of non-labor income. Further, individual, household and time specific characteristics $x_{i t}$ that are constant over the different labor supply alternatives, such as age or nationality enter the utility function. Moreover, if available, $x_{i t}$ includes the leisure time of the partner. These variables can be interpreted as taste shifters of the preferences for income and leisure. In addition, the utility is dependent on the realized

\footnotetext{
${ }^{9}$ The reduced-form dynamic life-cycle model can be seen as the myopic version of the fully dynamic life cycle model.

${ }^{10}$ We omit an explicit discussion of the resulting Bellman equations. For more detail, see e.g. Keane and Wolpin (2001).

${ }^{11}$ This assumption is supported by Steiner and Wrohlich (2004) who show that changes in workincentives of one spouse do hardly affect the working behavior of the partner. However, this is in contrast to e.g. van Soest (1995) who models the labor supply decision of couple households in a joint framework and even more to models that consider a collective model where both spouses are involved in a bargaining process to determine their individual leisure time and income (Vermeulen, 2002).
} 
working behavior of the men in the previous period $z_{i t-1}$ which consists of full-time and over-time work, and voluntary non-participation. This variable is constant over the alternatives and affects the preferences in the current period. The unobservable component consists of unobserved heterogeneity $c_{i j}$ that is different for the alternatives yet allowed to be correlated, and of a random error term that varies independently between time, households and alternatives $\epsilon_{i j t}$.

The maximization problem is subject to the following household budget constraint where consumption $C_{i t}$ equals the alternative specific income of the man, the income of other household members and further non-labor income which is the joint net household income

$$
C_{i t}=y_{i j t}
$$

In order to derive the joint net income for each household at all discrete working alternatives we apply the microsimulation model STSM. Based on variables drawn from the SOEP that determine gross income and certain deductible expenses for all household members, disposable net income is simulated at the household level ${ }^{12}$ This detailed modeling of the net household income is central for the estimation of the labor supply behavior, since the work incentives can be accurately described in the household context. In this respect we go beyond most of the empirical studies on intertemporal labor supply, e.g. Hyslop (1999) which do not explicitly model the net household income.

\subsection{Intertemporal Labor Supply Model Accounting for Invol- untary Unemployment}

As stressed above, a standard choice model of labor supply behavior is based on the assumption that each individual can freely choose his preferred labor market state and does not face any demand side constraints. Given the empirical relevance of involuntary unemployment, this seems to be a relatively strong assumption which might

\footnotetext{
12 Gross income of a household is calculated by adding all income components of the household members observed in the data. The income tax is computed by applying the income tax function to taxable income of each person in the household or of the spouses' joint income, depending on marital status. Income tax, the tax supplement and employee's social security contribution rates are deducted from gross income, and social transfers are added to derive the net household income. For more detail, see Steiner, Haan, and Wrohlich (2005).
} 
lead to inconsistent estimates of the labor supply behavior. A priori, the direction and size of inconsistency can not be determined because several factors might bias labor supply elasticities when not accounting for involuntary unemployment. Bargain, Caliendo, Haan, and Orsini (2006) discuss potential sources for the inconsistency in a static framework. Mainly a 'participation bias' and a 'preference bias' affect labor supply elasticities. The 'participation bias' leads to a clear upward bias of the labor supply elasticities from the unconstrained model because all involuntary unemployed are treated as voluntary inactive who can adjust their labor supply given a change in working incentives. The second important source of discrepancies is the "preference bias' stressed by Ham (1982) which acts in the opposite direction . In effect, ignoring involuntary unemployment necessarily leads to overstating of the taste for leisure in the estimates and, therefore, to understating of elasticities ${ }^{13}$ When analyzing the labor supply behavior in a dynamic context, the problem of inconsistency gets even more sever as all sources affect both the initial labor market state as well as the dynamic process.

In order to relax the assumption of a pure choice model we propose a more general framework of intertemporal labor supply behavior that accounts for the individual risk of involuntary unemployment and allows to derive labor supply elasticities not suffering from the inconsistencies discussed above. This model is an extension of the pure choice model, since we condition the individual labor supply choice on the individual probability of labor market rationing. In other words, a pure choice model is nested in the proposed framework of labor supply with demand side rationing. Both models are identical if there exists no rationing on the labor market, i.e. when the assumption of free choices is fullfilled.

The model we propose is an extension of the static double-hurdle model first suggested in this context by Blundell, Ham, and Meghir (1987). More precisely we combine the structural intertemporal choice model of labor supply described above with a reduced form intertemporal risk model of demand side rationing. Thus, we jointly account for state dependence and the individual risk of involuntary unemployment and provide therefore a model to consistently analyze the labor supply behavior over time.

\footnotetext{
${ }^{13}$ In addition, a labor supply model not accounting for involuntary unemployment is misspecified since individual characteristics are not only required to explain consumption-leisure preferences but also implicitly account for demand-side constraints.
} 
The first part of the model is the structural intertemporal labor supply model. The crucial difference relative to pure choice models is that in the framework here we treat voluntary non-participants and involuntary unemployed differently and assume for the latter that they obtain a higher utility when working than when not working.

The second part of the model reflects that each individual has a probability to be involuntary unemployed. Hence, despite a higher utility when working there is a risk not to realize the desired choice and to become involuntary unemployed. For a single men $i$, or the male spouse $i$ in a couple, we specify the following intertemporal latent equation of involuntary unemployment:

$$
I_{i t}^{*}=X_{i t} \beta_{d}+Z_{i t-1} \lambda+\mu_{i}+\eta_{i t}
$$

as a stochastic function of characteristics $X_{i t}$ thought to influence the probability of getting a job. $X_{i t}$ includes individual specific variables such as education and age and demand side variables describing the situation on the regional labor market. Moreover, we condition the rationing risk on the labor market status in the previous period $Z_{i t-1}$ which varies between over-time, full-time, involuntary unemployment and voluntary inactivity. The unobserved component in this model consists of an individual unobserved effect $\mu_{i}$ that is time constant and random terms $\eta_{i t}$ which are assumed to be independently distributed.

\section{State Dependence in Labor Supply with Involuntary Unem- ployment}

One key advance of the proposed framework is to extend the analysis of state dependence in labor supply by distinguishing between voluntary and involuntary unemployment. In this extended framework, state dependence affects both the demand and supply side of labor market. On the one hand, the lagged labor market status enters the utility flow in period $t$ which measures the supply side effect of state dependence. This effect is present if, given the observed and unobserved characteristics, the labor market status of the last period affects the current labor supply choice. This could arise if the employment history is relevant for prices, preferences and constraints of future periods (Heckman and Willis, 1977). Examples are intertemporally nonseparable preferences or habit formation. Further, fixed costs of work such as search or transaction 
costs are potential sources of state dependence, as these might differ by the previous employment state.

On the other hand, the rationing risk in the current period is affected by the previous labor market status. These effects ceteris paribus describe human capital accumulation, or signaling effects which differ by the employment history. State dependence might differ for voluntary non-participants and involuntary unemployment for several reason. Involuntary unemployment going along with an active searching for a job might have lower deterioration of human capital or induce different signals. By the same token, fixed costs might differ for the two labor market states.

Moreover, the job arrival rate should be higher for involuntary unemployed because they are actively looking for a job. This explanation of a causal effect of the previous labor market status on the current labor supply is different from the classical explanations of state dependence. Thus, when interpreting state dependence, or the causal effect of the previous labor market state in the empirical analysis this has to be taken into consideration.

State dependence can be positive or negative, yet as underlined by the given examples, the causal effect of last periods labor market status seems to be positive (Lee and Tae, 2005). In the empirical application, we test whether the effect of true state dependence is significantly positive in a model of labor supply. Therefore, we distinguish between the above mentioned sources of choice persistence: true state dependence and observed and unobserved heterogeneity. In addition, there might be a third source of choice persistence in the data coming from autocorrelation in the error terms $\epsilon_{i j t}$. Amongst others, Hyslop (1999) accounts for serial correlation. Yet, Croda and Kyriazidou (2005) and Michaud and Tatsiramos (2005) reject the hypothesis of a first order autoregressive process in a dynamic labor supply model using micro data for Germany. Moreover, since we account for the regional unemployment rate we capture all random shocks that affect the regional labor market. Therefore, we assume the error terms $\epsilon_{i j 1}$, ..., $\epsilon_{i j T}$ to be uncorrelated over time. 


\section{Econometric model}

In this section we develop the econometric framework for the empirical analysis. We develop an intertemporal labor supply framework and condition the labor supply choice on the risk of labor market rationing which allows us to consistently estimate the intertemporal working behavior of men.

\subsection{Labor Supply Behavior}

As derived above, in the labor supply model we assume that the level of utility at each discrete working choice $j$, non-work, full-time work, over-time work, can be expressed as

$$
V_{i j t}=U\left(l m_{i j t}, y_{i j t}, Z_{i t-1}, x_{i t}, c_{i j}, \epsilon_{i j t}\right)
$$

Drawing on McFadden (1974), we assume the error terms $\epsilon_{i j t}$ to follow a Gumble distribution. Then, a discrete choice model can be derived where the probability of choosing alternative $j$ from all $J$ alternatives is conditioned on the explanatory variables in period $t$, the labor market state of the previous period and the unobserved individual effect. In fact here, we slightly extend the standard conditional or multinomial logit framework and model the choice probabilities in a mixed logit framework (Cameron and Trivedi, 2005). This is a more general framework which allows for alternative specific random intercepts and alternative specific effects of the lagged dependent variable and at the same time for regressors varying over alternatives:

$$
\operatorname{Pr}\left(V_{i t}=j\right)=\frac{\exp \left(\tilde{U}_{i j t}+Z_{i t-1} \gamma_{j}+c_{i j}\right)}{\sum_{r=0}^{2} \exp \left(\tilde{U}_{i r t}+Z_{i t-1} \gamma_{r}+c_{i r}\right)}
$$

We model the lagged employment status as a vector of dummy variables consisting of voluntary unemployment, involuntary unemployment, full-time and over-time work. For identification it is necessary to restrict the coefficient vector of the lagged dependent variables $\gamma_{j}$ as well as the random intercept for one category to zero which is here the non-working alternative. $\tilde{U}_{i j t}$ contains the alternative specific variables and individual and household specific characteristics that are modelled as taste shifters. Coefficients of these variables do not vary between the alternatives. More precisely, 
we assume $\tilde{U}_{i j t}$ to follow a quadratic utility function of income and leisure, conditional on individual specific characteristics similar to Blundell, Duncan, McCrae, and Meghir (2000). Disposable net household income and the leisure of the man, interaction and quadratic terms enter the utility function. Hence, the $\tilde{U}_{i j t}$ to be estimated has the following form:

$$
\tilde{U}_{i j t}=\alpha_{1} y_{i j t}+\alpha_{2} l m_{i j t}+\alpha_{3} y_{i j t}^{2}+\alpha_{4} l m_{i j t}^{2}+\alpha_{5} y_{i j t} l m_{i j t}
$$

We assume that the marginal utility of income and leisure varies across households by age, education, number and age of children, region, health status, nationality, and for couple households by information about the female spouse:

$$
\begin{aligned}
& \alpha_{1}=\beta_{1}+\gamma_{1} x_{1 i t}, \\
& \alpha_{2}=\beta_{2}+\gamma_{2} x_{2 i t} .
\end{aligned}
$$

\subsection{Labor Supply with Labor Market Rationing}

In order to account for involuntary unemployment we condition the labor supply choice on the individual risk of labor market rationing. Denoting $d$ the desired hours of the choice framework and $p$ an indicator variable representing non-rationing, we can describe the working alternatives of men accounting for labor market rationing with three mutually exclusive states: to be voluntarily inactive with zero desired working hours $\operatorname{Pr}(d=0)$, to be rationed but with positive desired working hours $\operatorname{Pr}(d>0, p=$ $0)$ and to participate without being rationed $\operatorname{Pr}(d>0, p=1)$. Unfortunately, in the data we do not observe whether the involuntary unemployed would prefer full-time or over-time work. However, since they have positive desired hours their utility level when working must exceed their utility level of non-working. We use this information by describing the labor supply choice of the involuntary unemployed by $(1-\operatorname{Pr}(d=0))$.

$$
P_{i t}^{V O L}\left|c_{i}=\operatorname{Pr}\left(d_{i t}=0\right)\right| c_{i}=\frac{\exp \left(\tilde{U}_{i 0 t}+Z_{i t-1} \gamma_{0}+c_{i 0}\right)}{\sum_{r=0}^{2}\left(\exp \tilde{U}_{i r t}+Z_{i t-1} \gamma_{r}+c_{i r}\right)},
$$




$$
\begin{gathered}
P_{i t}^{I N V O L} \quad\left|c_{i}, \mu_{i}=\operatorname{Pr}\left(d_{i t}>0, p_{i t}=0\right)\right| c_{i}, \mu_{i} \\
=\left(1-\frac{\exp \left(\tilde{U}_{i 0 t}+Z_{i t-1} \gamma_{0}+c_{i 0}\right)}{\sum_{r=0}^{2}\left(\exp \tilde{U}_{i r t}+Z_{i t-1} \gamma_{r}+c_{i r}\right)}\right) \Lambda\left(X_{i t} \beta_{d}+Z_{i t-1} \lambda+\mu_{i}\right) \\
P_{i t}^{E M P} \quad\left|c_{i}, \mu_{i}=\operatorname{Pr}\left(d_{i t}>0, p_{i t}=1\right)\right| c_{i}, \mu_{i} \\
=\sum_{j=1}^{2} \frac{\exp \left(\tilde{U}_{i j t}+Z_{i t-1} \gamma_{1}+c_{i j}\right)}{\sum_{r=0}^{2}\left(\exp \tilde{U}_{i r t}+Z_{i t-1} \gamma_{r}+c_{i r}\right)}\left[1-\Lambda\left(X_{i t} \beta_{d}+Z_{i t-1} \lambda+\mu_{i}\right)\right]
\end{gathered}
$$

where $\Lambda$ expresses that the error terms $\eta_{i t}$ of the latent model of labor market rationing (Equation 3) follow a logistic distribution.

The observed intertemporal labor supply behavior accounting for demand side rationing does not coincide with the start of the stochastic process generating individual's employment dynamics and leads to the well known initial conditions problem. To take the potential non randomness of the initial working state into account we follow Heckman (1981b) and estimate a static reduced form discrete choice model for the initial labor market state $(t=0)$ without the lagged labor market status and different slope parameters ${ }^{14}$ Thus, the working behavior of men in the initial state $t=0$ can be expressed as conditional probabilities of the different labor market states:

$$
\begin{gathered}
P_{i 0}^{V O L}\left|\nu_{i}=\operatorname{Pr}\left(d_{i 0}=0\right)\right| \nu_{i}=\frac{\exp \left(\hat{U}_{i 00}+\nu_{i 0}\right)}{\sum_{r=0}^{2}\left(\exp \hat{U}_{i r 0}+\nu_{i r}\right)}, \\
P_{i 0}^{I N V O L} \quad\left|\nu_{i}, \kappa_{i}=\operatorname{Pr}\left(d_{i 0}>0, p_{i 0}=0\right)\right| \nu_{i}, \kappa_{i} \\
=\left(1-\frac{\exp \left(\hat{U}_{i 00}+\nu_{i 0}\right)}{\sum_{r=0}^{2}\left(\exp \hat{U}_{i r 0}+\nu_{i r}\right)}\right) \Lambda\left(\beta_{d 0} X_{i 0}+\kappa_{i}\right), \\
P_{i 0}^{E M P} \quad\left|\nu_{i}, \kappa_{i}=\operatorname{Pr}\left(d_{i 0}>0, p_{i 0}=1\right)\right| \nu_{i}, \kappa_{i} \\
=\sum_{j=1}^{2} \frac{\exp \left(\hat{U}_{i j 0}+\nu_{i j}\right)}{\sum_{r=0}^{2}\left(\exp \hat{U}_{i r 0}+\nu_{i r}\right)}\left[1-\Lambda\left(\beta_{d 0} X_{i 0}+\kappa_{i}\right)\right] .
\end{gathered}
$$

\footnotetext{
${ }^{14}$ An alternative approach to account for the potential non-randomness of the initial condition is to estimate the distribution of the unobserved effect conditional on the initial state and time invariant variables. This ends up in less complex estimation methods. However, in our model we do not observe the initial states of both processes for every individual. Therefore, we cannot apply the "simple solution" proposed by Wooldridge (2005).
} 
The unobserved effects affecting labor supply $\nu_{i j}$ are modelled as functions of the unobserved heterogeneity $c_{i j}$, and similarly we assume a relationship between the unobserved effects in the risk of rationing for the initial state and the dynamic process:

$$
\begin{gathered}
\nu_{i j}=\alpha_{\nu} c_{i j} . \\
\kappa_{i}=\alpha_{\kappa} \mu_{i} .
\end{gathered}
$$

The conditional individual likelihood contribution $L_{i}$ is described by the above defined conditional probabilities of the employment states:

$$
L_{i} \mid c_{i}, \mu_{i}=\prod_{t=1}^{T} \prod_{j=1}^{J} \operatorname{Pr}\left(Y_{i t}=j\right)^{d_{i t j}(t>0)} \operatorname{Pr}\left(Y_{i 0}=j\right)^{d_{i 0 j}(t=0)}
$$

where $d_{i t j}=1$ if $j$ is the chosen alternative in period $t$ and 0 otherwise.

\section{Unobserved heterogeneity}

We assume that the unobserved effects, $c_{i}$ and $\mu_{i}$, can be described by a discrete distribution in a two-factor loading model, assuming that two unobserved factors $V_{1}$ and $V_{2}$ enter the model. In the true intertemporal labor supply specification the unobserved heterogeneity is described by four probabilities $P\left(V_{1}=-1\right), P\left(V_{1}=1\right), P\left(V_{2}=\right.$ $-1), P\left(V_{2}=1\right)$ and six factor loadings, for the choice model $c_{1}^{1}, c_{1}^{2}, c_{2}^{1}, c_{2}^{2}$, and for the rationing model $\mu^{1}, \mu^{2}$. For identification, one of the factor loadings is set to be 0 , hence in total 5 factor loadings and 2 probabilities have to be estimated ${ }^{15}$ This model allows for full flexibility in the variance covariance matrix.

The sample likelihood for the intertemporal model accounting for involuntary unemployment is given by the product of the weighted individual likelihood contributions. The weights $\pi_{l}$ correspond to the probabilities of the four possible factor combinations $\left(\pi_{1}=P\left(V_{1}=-1\right) P\left(V_{2}=-1\right), \ldots, \pi_{4}=P\left(V_{1}=+1\right) P\left(V_{2}=+1\right)\right)$. The sample likelihood is given by

\footnotetext{
${ }^{15}$ For the estimation procedure the probabilities are specified as logistic probabilities to ensure that the probabilities vary between 0 and 1 and that the two probabilities of each factor add up to one.
} 


$$
L=\prod_{i=1}^{n} \sum_{l=1}^{4} \pi_{l} L_{i l} .
$$

\section{$5 \quad$ Empirical Results}

\subsection{Estimation Results}

Table 4 yields the estimation results of the above specified model of intertemporal labor supply. In addition to the model accounting for involuntary unemployment (models III and IV) we present results for a pure intertemporal choice model (models I and II). The latter can be seen as a special case of the model with rationing where we assume that the rationing risk is zero. We present the estimation of both models to illustrate the implications of the different assumptions and to assess the potential bias of the estimated labor supply behavior in a pure choice model, which is discussed in detail at the end of this section.

In addition to the specifications controlling for unobserved effects (models II and IV) we present results derived from estimations without unobserved heterogeneity (models I and III). As expected, we find for both classes of models a significant improvement in the likelihood function and a large reduction in the Akaike Information Criterion when introducing unobserved heterogeneity 16 As stressed above unobserved effects partly explain the persistence in the labor supply behavior of men. Therefore, we find a significantly reduced effect of the lagged labor market status on the current working behavior when accounting for unobserved heterogeneity. The correlation coefficient $\rho_{12}$ is around 0.4 in the pure choice model and around 0.2 in the model with involuntary unemployment. This indicates that unobserved characteristics which lead to full-time and over-time work are similar but different from unobserved characteristics of not participating individuals. Moreover, the correlation coefficients $\rho_{13}(-0.86)$ and $\rho_{23}$ (0.67 ) indicate that unobserved characteristics leading to full-time and over-time work are different from characteristics leading to involuntary unemployment. This result is quite intuitive. If we think for example of motivation for work as an unobserved

\footnotetext{
${ }^{16}$ The Akaike Information Criterion (AIC) rather than a standard likelihood ratio test has to be considered as under the null hypothesis the latter violates the regularity conditions, and thus its distribution is unknown. AIC is defined as $A I C=-2 \ln L+2 k$, where $\ln L$ is the log likelihood at the maximum and $k$ the number of estimated parameters.
} 
Table 4: Estimation Results

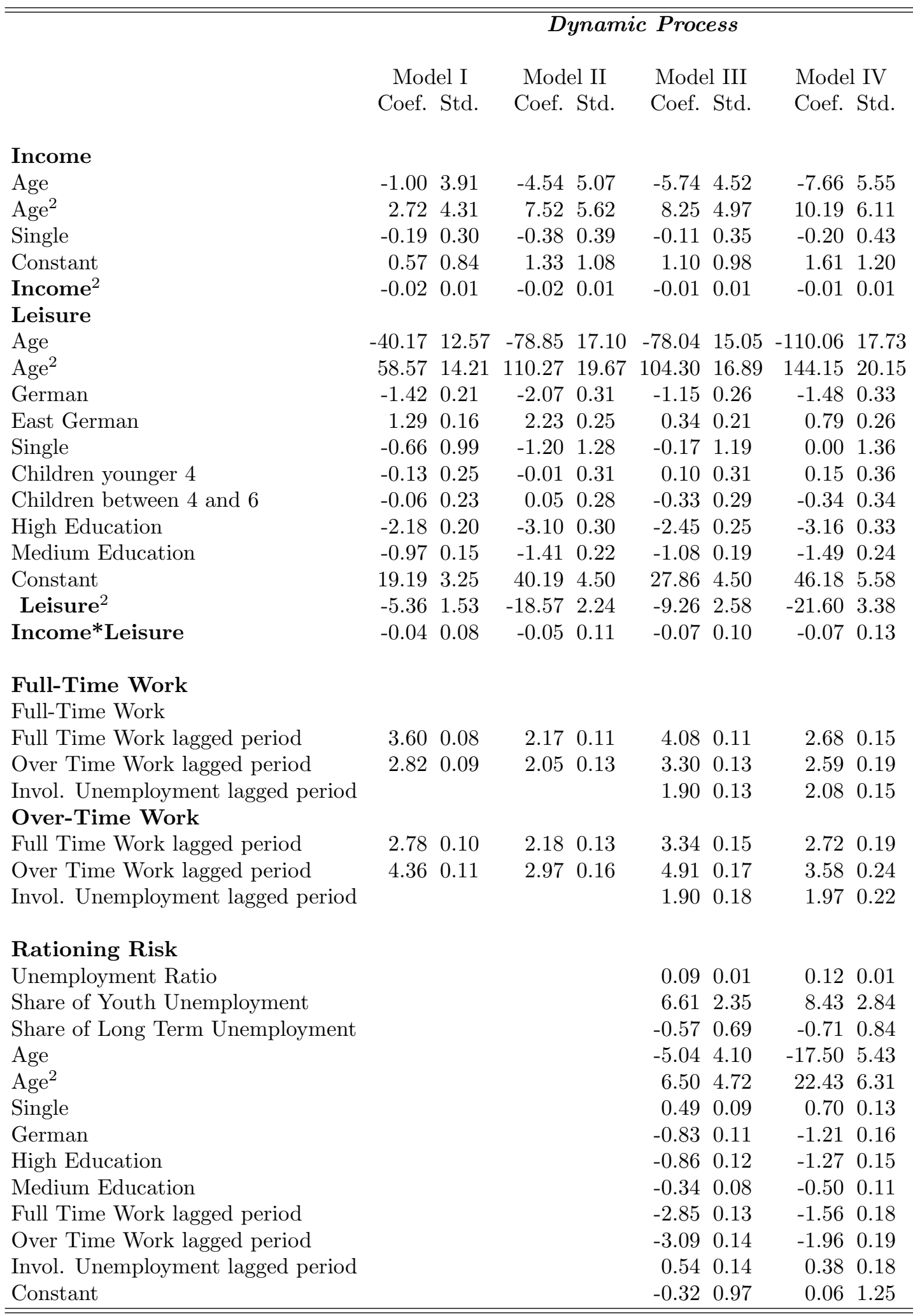


Initial State

Income
Age
Age $^{2}$
Single
Constant
Income
Leisure
Age
Age
German
East German
Single
Children younger 4
Children between 4 and 6
High Education
Medium Education
Constant
Initial Leisure
Income*Leisure
Rationing Risk
Unemployment Ratio
Share of Youth Unemployment
Share of Long Term Unemployment
Age
Age
Single
German
High Education
Medium Education
Constant

$\begin{array}{rrrrrrrl}-6.30 & 6.53 & -11.60 & 8.42 & -12.59 & 7.87 & -19.25 & 9.50 \\ 7.63 & 7.50 & 14.43 & 9.72 & 17.32 & 8.96 & 25.10 & 10.89 \\ 0.20 & 0.52 & 0.03 & 0.68 & -0.85 & 0.62 & -1.32 & 0.77 \\ 2.58 & 1.32 & 3.60 & 1.67 & 3.97 & 1.60 & 5.46 & 1.91 \\ -0.04 & 0.01 & -0.05 & 0.01 & -0.02 & 0.01 & -0.03 & 0.02 \\ & & & & & & & \\ -58.47 & 18.87 & -99.69 & 24.97 & -87.32 & 25.23 & -127.53 & 28.96 \\ 76.20 & 22.39 & 129.02 & 29.78 & 120.42 & 29.55 & 170.27 & 34.33 \\ -1.32 & 0.34 & -1.76 & 0.48 & -1.25 & 0.43 & -1.42 & 0.57 \\ 1.14 & 0.27 & 2.06 & 0.37 & -0.40 & 0.37 & -0.13 & 0.45 \\ 1.79 & 1.49 & 2.19 & 1.98 & -1.67 & 1.98 & -1.53 & 2.31 \\ -0.05 & 0.39 & 0.21 & 0.52 & -0.55 & 0.51 & -0.69 & 0.65 \\ -0.51 & 0.39 & -0.77 & 0.50 & -0.51 & 0.50 & -0.79 & 0.63 \\ -2.02 & 0.35 & -2.46 & 0.46 & -2.08 & 0.43 & -2.10 & 0.54 \\ -0.49 & 0.25 & -0.64 & 0.34 & -0.35 & 0.32 & -0.47 & 0.41 \\ 32.70 & 3.76 & 47.30 & 5.24 & 42.96 & 5.01 & 58.73 & 6.34 \\ -19.27 & 0.77 & -26.63 & 1.69 & -24.54 & 0.90 & -34.72 & 3.14 \\ -0.40 & 0.17 & -0.25 & 0.21 & -0.43 & 0.20 & -0.27 & 0.25\end{array}$

$\begin{array}{rrrr}0.18 & 0.01 & 0.18 & 0.02 \\ 7.40 & 4.37 & 6.40 & 5.16 \\ -2.08 & 1.07 & -2.18 & 1.28 \\ -15.91 & 6.17 & -26.22 & 7.59 \\ 19.30 & 7.43 & 32.71 & 9.16 \\ 0.68 & 0.16 & 0.81 & 0.20 \\ -1.00 & 0.21 & -1.23 & 0.26 \\ -1.37 & 0.22 & -1.55 & 0.25 \\ -0.50 & 0.15 & -0.50 & 0.18 \\ -0.90 & 1.46 & 0.04 & 1.77\end{array}$

\section{Unobserved Heterogeneity}

Mass 1

$\begin{array}{ll}0.56 & 0.12\end{array}$

$0.28 \quad 0.15$

$\begin{array}{ll}1.29 & 0.04\end{array}$

$\begin{array}{ll}1.51 & 0.10\end{array}$

$\begin{array}{ll}-1.23 & 0.04\end{array}$

Mass 3

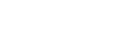

$1.25 \quad 0.14$

Mass 4

Mass 5

Mass 1 Initial

Mass 2 Initial

$\begin{array}{ll}0.93 & 0.17\end{array}$

$2.00 \quad 0.16$

$\begin{array}{ll}1.32 & 0.06\end{array}$

$\begin{array}{ll}-1.18 & 0.13\end{array}$

$\begin{array}{ll}1.29 & 0.13\end{array}$

Mass 3 Initial

Mass 4 Initial

Mass 5 Initial

$\rho_{12}$

0.390 .07

$\begin{array}{ll}1.36 & 0.53\end{array}$

$\begin{array}{ll}-1.25 & 0.06\end{array}$

2.390 .52

$\begin{array}{ll}-1.35 & 0.17\end{array}$

$\begin{array}{ll}1.38 & 0.20\end{array}$

$\begin{array}{ll}0.22 & 0.12\end{array}$

$\begin{array}{lll}-0.86 & 0.07\end{array}$

$\begin{array}{ll}-0.67 & 0.05\end{array}$

$\rho_{23}$

Probability 1

$\begin{array}{lll}0.57 & 0.03\end{array}$

$\begin{array}{ll}0.54 & 0.03\end{array}$

Probability 2

$\begin{array}{lll}0.52 & 0.02\end{array}$

$\begin{array}{ll}0.50 & 0.02\end{array}$

\begin{tabular}{lcccc} 
Log-likelihood & -19237.94 & -18613.50 & -20774.05 & -20168.78 \\
Akaike Criterion & 38597.88 & 37365.01 & 41728.10 & 40541.56 \\
\hline
\end{tabular}

Number of observation 20667. Time dummies, information of the spouse and health information are included in analysis but are not reported. Variables are defined in Table 7

Source: SOEP, wave 2000-2005. 
characteristic, this should have a positive impact on the probability of participating in the labor market and a negative impact on the probability of not finding a job, which corresponds to the negative correlation coefficient.

For the interpretation of effects with multiple interactions, such as income and leisure, marginal effects, derivatives or elasticities need to be considered. Empirical derivatives with respect to leisure and income show that the theoretical implications of the utility function are fulfilled. For the majority of households, the concavity of the utility with respect to income and leisure is guaranteed ${ }^{17}$

Preference for income and leisure vary with observed characteristics, such as education, number of children, age or region. Regardless of the specification, preferences for income do hardly vary significantly with observed characteristics. In contrast, preferences for leisure significantly differ across the population. The effects are similar in the pure choice model and in the labor supply model accounting for involuntary unemployment. Better educated men have a significant higher inclination for work. The estimation exhibit the expected age pattern, taste for work is increasing yet at a diminishing rate. Non-German men have a slightly higher taste for work than German men, while we find a lower taste for men living in east Germany. This effect, however, is reduced when we control for the labor market constraints which capture the higher risk of unemployment in the eastern part. In contrast to studies on the labor supply of women, e.g. Bargain, Caliendo, Haan, and Orsini (2006), we do not find different preferences for single men and men living in couple households, and we find no significant effects of young children.

Turning to the estimation of the rationing risk, we find a strong and significant impact of the regional labor market indicators on the individual rationing risk. The risk increases significantly with regional unemployment rates and with the share of youthunemployment while the share of long term unemployed is not statistically significant. The individual characteristics have the expected pattern. The risk of rationing is significantly lower for single men, better educated and for natives.

The coefficients of the lagged dependent variables hint at positive state dependence in the labor supply behavior of men, though the interpretation can be only seen as

\footnotetext{
${ }^{17}$ For over $95 \%$ of the sample the first derivative with respect to income and leisure are positive, while the second are for all negative.
} 
indicative. We find positive and significant effects of employment in the previous period on working in the current period.

\subsection{State Dependence in Labor Supply Behavior}

In order to analyze the effect of true state dependence in male labor supply behavior, we derive an intertemporal transition matrix of working behavior conditional on observable and unobservable effects. This transition matrix of working behavior is calculated based on the conditional probabilities for each working category.

\section{Posterior Probability of Discrete Alternatives}

The conditional probabilities for each working category depend on the unobserved individual specific effects. Therefore, it is necessary to draw from the posterior choice probability that is conditioned on the individual choice sequence. This conditional probability explicitly accounts for the unobserved heterogeneity by assigning unobserved characteristics to each individual (Skrondal and Rabe-Hesketh, 2004). We derive the posterior probabilities by calculating household specific weights for the four different factor combinations. The individual specific weights $w_{i l}$ are defined in the following way:

$$
w_{i l}=\frac{P\left(\tilde{y}_{i l} \mid \mathbf{X}_{\mathbf{i}}, a_{i}^{l}\right)}{\sum_{l=1}^{4} P\left(\tilde{y}_{i l} \mid \mathbf{X}_{\mathbf{i}}, a_{i}^{l}\right)},
$$

where vector $\left(\tilde{y}_{i l}\right)$ captures the chosen sequence of working alternatives conditioned

on factor combination $l$ and matrix $\mathbf{X}_{i}$ that includes all explanatory variables over the observed period. The higher the probability of the chosen sequence given the factor combination the higher the weight assigned to the combination. Skrondal and RabeHesketh (2004) provide a detailed description of this method, sometimes referred to as Empirical Bayes, and discuss the properties of the prediction.

\section{State Dependence in a Rationed Labor Market}

Conditional on the estimated coefficients of the lagged dependent variables, we describe the transition process of labor supply by calculating a transition matrix $\mathbf{M}$ (Table 5). In the columns of the transition matrix the previous employment state is tabled, the 
rows show the probability of the working alternative in the current period. The matrix yields the average of the predicted individual conditional probabilities.

Since unobserved and observed characteristics are kept constant within each column and only the lagged labor market status is varied, the transition matrix provides information about true state dependence. All differences in the labor supply behavior conditioned on period $t-1$ can be attributed to the previous employment status which is the effect of true state dependence ${ }^{18}$ The estimated true state dependence between the working categories is simply the difference in the probability within a column.

More formally, state dependence e.g. in full-time work conditional on full-time work in the previous period versus conditional on employment status $k$ is calculated as:

$$
\operatorname{Pr}\left(j_{t} \mid j_{t-1}\right)-\operatorname{Pr}\left(j_{t} \mid k_{t-1}\right)
$$

where, in this example, $j$ represents full-time work and $k$ any other employment status.

One key advance of the suggested framework is the possibility to empirically analyze state dependence in the labor supply behavior of men in a rationed labor market. Thus, it is possible to derive state dependence not only between work and non-work, but between voluntary non-participation, involuntary unemployment, full-time and parttime work. As we find significant difference in the state dependence between voluntary participation and involuntary unemployment, we only consider the transition matrix of the model accounting for involuntary unemployment. For comparison, we present the transition matrix of the pure choice model in the Appendix.

According to the bootstrapped standard errors, all conditional probabilities are very precisely estimated. The transition matrix shows that true state dependence is significantly present between all working states. We find a striking difference in the state dependence for full-time work conditional on being voluntary (0.155) or involuntary unemployed (0.045) in the previous period. For over-time work the state dependence is higher for both groups and the difference between the two states of non-employment is smaller though still significant. Overall, this result implies that involuntary unemployed men who actively search for a job have a significantly higher probability of working

\footnotetext{
${ }^{18}$ Uhlendorff (2006) applies a similar approach when testing for state dependence in income dynamics.
} 
Table 5: Statedependence with Involuntary Unemployment

\begin{tabular}{|c|c|c|c|c|}
\hline & Vol. Non-Part. & Inv. Unemp. & Full-Time & Over-Time \\
\hline Vol. Non-Part. (t-1) & $\begin{array}{l}0.241 \\
0.018\end{array}$ & $\begin{array}{l}0.051 \\
0.008\end{array}$ & $\begin{array}{l}0.460 \\
0.022\end{array}$ & $\begin{array}{l}0.247 \\
0.024\end{array}$ \\
\hline Inv. Unempl. (t-1) & $\begin{array}{l}0.062 \\
0.005\end{array}$ & $\begin{array}{l}0.086 \\
0.014\end{array}$ & $\begin{array}{l}0.569 \\
0.019\end{array}$ & $\begin{array}{l}0.282 \\
0.021\end{array}$ \\
\hline Full-time (t-1) & $\begin{array}{l}0.039 \\
0.002\end{array}$ & $\begin{array}{c}0.0158 \\
0.004\end{array}$ & $\begin{array}{l}0.611 \\
0.008\end{array}$ & $\begin{array}{l}0.335 \\
0.005\end{array}$ \\
\hline Over-time (t-1) & $\begin{array}{l}0.029 \\
0.003\end{array}$ & $\begin{array}{l}0.012 \\
0.002\end{array}$ & $\begin{array}{l}0.473 \\
0.007\end{array}$ & $\begin{array}{l}0.487 \\
0.008\end{array}$ \\
\hline
\end{tabular}

The following working hours classifications (weekly) are used: 0, 0-40, >40.

All numbers are in shares.

Source: SOEP, wave 2000-2005.

in the next period. Moreover, we show that the conditional probability of voluntary non-participation is significantly different for both groups. Whereas the probability of voluntary inactive to remain in this alternative is close to $25 \%$, the probability for this alternative is about $6 \%$ for previously involuntary unemployed.

Conditional on full-time and over-time work we find very low probabilities of both voluntary or involuntary inactivity. In contrast, we show that the conditional persistence of work is very high. Still, on the intensive margin, there is significant state dependence between full-time and over-time. This suggests that the above discussed sources of state dependence, such as intertemporally non-separable preferences, affect not only labor market participation but as well the intensive margin when working.

\subsection{Labor Supply Elasticities}

In order to analyze the effects of financial incentives on the labor supply behavior we derive labor supply elasticities. This is the variable of central interest when discussing labor supply, since this is the channel where policy might affect the working behavior by reforming the tax and benefit system. The intertemporal model of labor supply allows to derive supply effects over time.

As labor supply elasticities cannot be derived analytically within the employed discrete choice framework, we simulate numerically average population changes in the labor market participation and weekly working hours induced by a $1 \%$ increase in 
net-household income when working. The elasticities are derived by calculating the simulated change in the predicted hours of work and in the participation rates. For the prediction of the working hours and the participation rate, we derive conditional transition matrices ${ }^{19}$ under two different scenarios, the status quo and a simulated scenario that differs by a $1 \%$ increase in net-household income when working. Given the transition matrix and assuming a first order Markov transition process, we calculate transition matrices for future periods. The advantage of this procedure is that stochastic transition matrices conditional on the previous labor market status can be simply derived not only for period $t$ but as well for future periods $t+k$. Elasticities derived after the first period are defined as the short term elasticities. A Markov process converges in the long run. Formally, the steady state is reached if $t \rightarrow \infty$. Empirically, the steady state is reached if a further period does not affect the transition matrix and the labor supply elasticities converge i.e. if they do not differ significantly. ${ }^{20}$

We derive the labor supply elasticities over time for both models, the pure choice framework and the framework where we account for involuntary unemployment. The comparison of these elasticities illustrates the bias of labor supply effects induced in a pure choice model.

The modeling of the rationing risk is reduced form. Therefore, we cannot assess directly the effects of changes in the net household income on the rationing risk e.g. through wage adjustment or changes in vacancy rates simultaneous to labor supply responses. Our analysis is partial in this respect, since we must assume that the individual rationing probability is not affected. Still this framework provides the possibility to derive in addition to labor supply elasticities, employment elasticities that reflect the individual rationing risk. Employment and labor supply elasticities differ, since the latter focuses solely on the working choice of individuals. Potential labor market constraints are not relevant for this measure. In the following, we concentrate the analysis on labor supply elasticities, since this measure is comparable for both specifications, with and without modeling involuntary unemployment. ${ }^{21}$.

\footnotetext{
${ }^{19}$ The conditional transition matrix makes use of the observed distribution of the employment status in the population. This is in contrast to the unconditional transition matrix which we derived to calculate state dependence.

${ }^{20} \mathrm{~A}$ detailed discussion of this method is provided in Haan (2006).

${ }^{21}$ Given the low labor supply response to the induced work incentives, employment and labor supply elasticities hardly differ. As stressed above on average less than $5 \%$ of men with positive desired hours
} 
Table 6: Labor Supply Elasticities with Involuntary Unemployment

\begin{tabular}{lcccc}
\hline \hline Period & \multicolumn{2}{c}{ Labor Market Participation } & \multicolumn{2}{c}{ Working Hours } \\
& Constrained & Unconstrained & Constrained & Unconstrained \\
\hline 1 & 0.0140 & 0.0437 & 0.0156 & 0.0470 \\
& $(0.0054-0.0226)$ & $(0.0324-0.0546)$ & $(0.0046-0.0268)$ & $(0.0338-0.0605)$ \\
2 & 0.0227 & 0.0738 & 0.0247 & 0.0786 \\
& $(0.0086-0.0360)$ & $(0.0551-0.0925)$ & $(0.0078-0.0438)$ & $(0.0578-0.1017)$ \\
3 & 0.0283 & 0.0942 & 0.0302 & 0.0999 \\
& $(0.0106-0.0443)$ & $(0.0709-0.1186)$ & $(0.0101-0.0548)$ & $(0.0746-0.1296)$ \\
4 & 0.0320 & 0.1081 & 0.0336 & 0.1140 \\
& $(0.0117-0.0493)$ & $(0.0818-0.1364)$ & $(0.0117-0.0619)$ & $(0.0864-0.1484)$ \\
5 & 0.0344 & 0.1174 & 0.0357 & 0.1234 \\
& $(0.0124-0.0524)$ & $(0.0893-0.1486)$ & $(0.0128-0.0665)$ & $(0.0946-0.1610)$ \\
\hline \hline
\end{tabular}

The 5th and 95th percentiles are given in brackets they are derived using bootstrapping with 1000 replications.

Elasticities are numerically derived, calculating the relative increase in the expected weekly working hours and in the probability of participation given a $1 \%$ change of net-income when working.

Source: SOEP, wave 2000-2005.

In Table 6, we present the labor supply elasticities with respect to weekly working hours and to the labor market participation over time. For both models with and without accounting for involuntary unemployment we find that labor supply elasticities significantly increase over time. In the short run (in the first period), state dependence prevents individuals to fully adjust their labor supply. Only in the long run, i.e. starting form the second period, when state dependence looses its significance, labor supply fully adjusts to a new steady state. Regardless of the specification, elasticities seem to double in the long run 22

When comparing the elasticities of the two different specifications we find that elasticities are significantly upward biased when not reflecting involuntary unemployment. Elasticities derived in the pure choice model are about three times higher. This difference is stable over time. In all periods elasticities are significantly higher in the model which assumes that all unemployment is voluntary. These results highlight the bias of the estimated labor supply behavior when not properly accounting for demand side constraints. As discussed above, intertemporal labor supply elasticities derived in a model without demand side constraints might be biased for several reasons and a priori the direction of the inconsistency is not clear. In our empirical analysis we show are restricted and this probability would explain the difference.

${ }^{22}$ Further periods did not affect the long run labor elasticities. 
that the upward bias is clearly dominating which stresses the relative importance of the participation bias.

First, as outlined above the model is misspecified because involuntary unemployed with positive desired hours are treated as voluntary inactive. This leads to inconsistent estimates of the preferences for income and leisure. Moreover, the dynamic transition process between the labor market states is not correctly described in a model without involuntary unemployment. As we have shown state dependence significantly differs between voluntary and involuntary unemployment. By the same token, the initial labor market status can only be consistently estimated when accounting for demand side constraints.

\section{Conclusion}

In this paper we propose a model to consistently estimate the intertemporal labor supply behavior. This model belongs to the class of models describing life cycle employment with approximate decision rules. In this framework we distinguish between voluntary non-participation and involuntary unemployment which is caused by labor market rationing and account for the effect of true state dependence. The proposed model extends previous studies on labor supply since they either not reflect the dynamics in labor supply behavior or are based on the assumption of a pure choice model which implies that unemployment is voluntarily chosen.

We apply the proposed intertemporal labor supply models with demand side rationing to consistently estimate the labor supply behavior of men over time. We find that true state dependence is significantly present between the different labor market states. Moreover, our results stress the necessity to account for involuntary unemployment when analyzing the intertemporal labor supply behavior, since state dependence differs significantly conditioned on involuntary unemployment and voluntary non-participation. Furthermore, we find that intertemporal labor supply elasticities significantly differ when accounting for involuntary unemployment. Elasticities derived in an unconstrained pure choice model are significantly upward-biased. This holds both for short run and long run effects. 


\section{References}

Ashenfelter, O. (1980): "Unemployment as Disequilibirium in a Model of Aggregate Labor Supply," Econometrica, 48, 547-664.

Bargain, O., M. Caliendo, P. HaAn, and K. Orsini (2006): "Making Work Pay' in a Rationed Labour Market," IZA Discussion-Paper, 2033.

Bingley, P., And I. Walker (1997): "The Labour Supply, Unemployment and Participation of Lone Mothers in In-Work Transfer Programmes," Economic Journal, 107.

Blundell, R., A. Duncan, J. McCrae, and C. Meghir (2000): "The Labour Market Impact of the Working Families' Tax Credit," Fiscal Studies, 21(1), 75-104.

Blundell, R., J. Ham, and C. Meghir (1987): "Unemployment and female labour supply," Economic Journal, 97, 44-64.

Blundell, R., and I. Walker (1986): "A Life-Cycle Consistent Empirical Model of Family Labor Supply Using Cross-Sectional Data," Review of Economic Studies, $53,539-558$.

Cameron, C., And P. K. Trivedi (2005): Microeconometrics. Methods and Applications. Cambridge University Press, New York.

Croda, E., And E. Kyriazidou (2005): "Intertemporal Labor Force Participation of Married Women in Germany: a Panel Data Analysis," Discussion paper.

Del Boca, D., and R. Sauer (2006): "Life Cycle Employment and Fertility Across Institutional Environments," IZA Discussion Paper, 2285.

Duncan, A., and J. MaCCrae (1999): "Household Labour Supply, Childcare Costs and In-Work Benefits: Modelling the Impact of the Working Families Tax Credit in the UK," Discussion paper.

Francesconi, M. (2002): "A Joint Dynamic Model of Fertility and Work of Married Women," Journal of Labor Economics, 20, 336-380. 
Frijters, P., ANd B. VAn Der KlaAuw (2006): "Job search with nonparticipation," Economic Journal, 116, 45-83.

HaAn, P. (2006): "Slowly but Changing: How Does Genuine State Dependence Affect Female Labor Supply On The Extensive And Intensive Margin?," JEPS Working paper, 0602.

Haisken De-New, J., And J. Frick (2005): Desktop Compendium to The German Socio-Economic Panel Study (SOEP). DIW, Berlin.

Hajivassiliou, V., And Y. IOAnnides (2007): "Unemployment and Liquidity Constraints," Journal of Applied Econometrics.

Ham, J. (1982): "Estimation of a Labour Supply Model with Censoring Due to Unemployment and Underemployment," Review of Economic Studies, 49, 335-354.

Heckman, J. (1981a): "Heterogeneity and State Dependence," in Studies in Labor Markets, ed. by S. Rosen, pp. 91-139. Chicago Press, Chicago, IL.

(1981b): "The Incedental Parameter Problem and the Problem of Initial Conditions in Estimating a Discrete Time-Discrete Data Stochastic Process," in Structural Analysis of Discrete Data with Econometric Applications, ed. by C. Manski, and D. McFadden, pp. 179-195. MIT Press, Cambridge, MA.

Heckman, J., And R. Willis (1977): "A Beta-logistic Model for the Analysis of Sequential Labor Force Participation by Married Women," Journal of Political Economy, 85, 27-58.

Hogan, V. (2004): "The Welfare Cost of Taxation In a Labor Market With Unemployment and Non-participation," Labor Economics, 11, 395-413.

Hyslop, D. (1999): "State dependence, serial correlation and heterogeneity in intertemporal labor force participation of married women," Econometrica, 67, 12551294.

Keane, M., and K. Wolpin (2001): "Estimating Welfare Effects Consistent with Forward-Looking Behavior: Part II: Empirical Results," Journal of Human Resources, $37,600-622$. 
Laroque, G., And B. Salanie (2002): "Labour Market Institutions and Employment in France," Journal of Applied Econometrics, 7, 25-48.

LEE, M.-J., AND Y.-H. TAE (2005): "Analysis of Labour Participation Behaviour of Korean Women with Dynamic Probit and Conditional Logit," Oxford Bulletin of Economics and Statistics, 67, No.1, 71-91.

McFadden, D. (1974): "Conditional Logit Analysis of Qualitative Choice Behavior," in Frontiers in Econometrics, ed. by P. Zarembka. Academic Press, New York.

Michaud, P., And K. Tatsiramos (2005): "Employment Dynamics of Married Women in Europe," IZA Discussion-Paper, 1704.

Michaud, P., And F. Vermeulen (2004): "A collective retirement model: identification and estimation in the presence of externalities," IZA Discussion-Paper, 1294.

Prowse, V. (2005): "State Dependence in a Multi-State Model of Employment Dynamics," IZA Discussion-Paper, 1623.

Skrondal, A., and S. Rabe-Hesketh (2004): Generalized Latent Variable Modeling. Chapman and Hall, Boca Raton, Florida.

Steiner, V., P. HaAn, and K. Wrohlich (2005): "Dokumentation des SteuerTransfer-Mikrosimulationsmodells 1999-2002," Data Documentation 9.

Steiner, V., And K. Wrohlich (2004): "Household Taxation, Income Splitting and Labor Supply Incentives. A Microsimulation Study for Germany," CESifo Economic Studies, 50, 541-568.

UhlendorfF, A. (2006): "From no pay to low pay and back again? A multi-state model of low pay dynamics," DIW-Discussion Paper, 648.

VAn Soest, A. (1995): "Structural Models of Family Labor Supply: A Discrete Choice Approach," Journal of Human Resources, 30, 63-88.

Vermeulen, F. (2002): "Collective household models: principles and main results," Journal of Economic Surveys, 16, 533-564. 
Wooldridge, J. (2005): "Simple Solutions to the Initial Conditions Problem for Dynamic, Nonlinear Panel Data Models with Unobserved Heterogeneity," Journal of Applied Econometrics, 20, 39-54. 


\section{Appendix}

Table 7: Descriptive Statistics by Working Alternatives

\begin{tabular}{lccccccc}
\hline & \multicolumn{2}{c}{ Share } & Low Education & German & East German & Bad health & Single Children \\
& & & & & & \\
& & & & & & \\
Vol. Non-Participation & 0.05 & 0.23 & 0.88 & 0.26 & 0.22 & 0.23 & 0.14 \\
Inv. Unemplyment & 0.05 & 0.17 & 0.87 & 0.37 & 0.11 & 0.29 & 0.16 \\
Full-Time & 0.52 & 0.10 & 0.91 & 0.17 & 0.08 & 0.21 & 0.18 \\
Over-Time & 0.38 & 0.06 & 0.94 & 0.18 & 0.04 & 0.17 & 0.20 \\
Average & & 0.10 & 0.92 & 0.19 & 0.08 & 0.20 & 0.18 \\
\hline \hline
\end{tabular}

The following working hours classifications (weekly) are used: 0, 0-40, >40.

Low education is the share of men with less than 10 years of schooling.

German is the share with German nationality.

East German is the share living in East Germany.

Bad health is the share of men disability higher $50 \%$.

Single is share of single households.

Young Children is share of households with children younger than 6 years.

Source: SOEP, wave 2000-2005.

Table 8: Statedependence without Involuntary Unemployment

\begin{tabular}{|c|c|c|c|}
\hline & Non-Work & Full-Time & Over-Time \\
\hline \multirow[t]{2}{*}{ Non-Work (t-1) } & 0.267 & 0.476 & 0.257 \\
\hline & 0.012 & 0.015 & 0.015 \\
\hline \multirow[t]{2}{*}{ Full-Time (t-1) } & 0.074 & 0.600 & 0.327 \\
\hline & 0.003 & 0.005 & 0.005 \\
\hline \multirow[t]{2}{*}{ Over-Time (t-1) } & 0.062 & 0.473 & 0.465 \\
\hline & 0.004 & 0.007 & 0.006 \\
\hline
\end{tabular}

The following working hours classifications (weekly) are used: $0,0-40,>40$.

All numbers are in shares.

Bootstrapped standard with 100 replication errors are in parenthesis.

Source: SOEP, wave 2000-2005. 